\title{
DOCUMENTO HISTÓRICO NO ENSINO MÉDIO: ANÁLISE DA PRODUÇÃO DE ALUNOS EM AULAS DE TEORIA DE GRAFOS
}

\section{HISTORIC DOCUMENT IN HIGH SCHOOL: ANALYSIS OF STUDENTS PRODUCTION IN GRAPH THEORY LESSONS}

\author{
Lauro Chagas e Sá, Sandra Aparecida Fraga da Silva \\ Instituto Federal do Espírito Santo \\ E-mail: lauro.sa@ifes.edu.br, sfraga@ifes.edu.br
}

\section{Resumo}

Este artigo analisa a produção de alunos de Ensino Médio em aulas sobre Teoria de Grafos, de modo a estabelecer relações entre suas estratégias de resolução e a do matemático Leonard Euler. Escolhemos para apresentar neste trabalho resoluções de uma carta, que adapta um documento histórico do Problema das Sete Pontes de Königsberg (1736) à disposição geográfica da Grande Vitória (Espírito Santo, Brasil). Esta atividade integra uma sequência didática para a introdução de Teoria de Grafos em turmas de segundo ano de ensino médio em uma escola estadual de Vitória-ES. A atividade foi desenvolvida para uma pesquisa de natureza qualitativa em nível de trabalho de conclusão de curso universitárioa. Com essa experiência, concluímos que a História da Matemática na abordagem da Teoria dos Grafos no Ensino Médio promove apropriação do conhecimento. Também verificamos que a perspectiva histórica permite mostrar que a matemática é uma ciência em contínuo desenvolvimento e que este processo é fruto de trabalho de diversas pessoas.

Palavras-chave: Matemática Discreta. teoria de Grafos. história da Matemática. Ensino Médio.

\section{Abstract}

This article looks at the production of high school students in classes on Graph Theory in order to establish links between their solving strategies and the strategies of the mathematics Leonard Euler. We chose to present in this paper a resolutions' letter of adapting a historical document of the Problem of the Seven Bridges of Königsberg (1736) to the geographical layout of Vitória (Espírito Santo, Brazil). This activity is part of a didactic sequence for the introduction of Graph Theory in a second year class of a state high school in Vitória-ES. The activity was developed for a qualitative research as a final concluding written work for universitary level. With this experience, we concluded that the History of Mathematics used as an approach of Graph Theory in high school promotes appropriation of knowledge. We also verified that historical perspective allows us to show that mathematics is a continually developing science and that this process is the result work of several people.

Palavras-chave: Discrete Mathematics. Graph theory. history of Mathematics. High School. 


\section{INTRODUÇÃO}

No Ensino Médio brasileiro, percebe-se que a Matemática Discreta tem se reduzido ao estudo de análise combinatória e probabilidade. Dessa forma, a inclusão dos Grafos no Ensino Médio permite a ampliação de discussões sobre os tópicos deste campo da matemática. Alguns aspectos normativos reforçam as potencialidades de se abordar a Matemática Discreta e a Teoria dos Grafos no Ensino Médio em sala de aula. As Orientações Educacionais Complementares aos Parâmetros Curriculares Nacionais defendem que "estar formado para a vida significa mais do que reproduzir dados, denominar classificações ou identificar símbolos. Significa [...] enfrentar problemas de diferentes naturezas" (BRASIL, 2002, p. 9). Nesse sentido, estudar elementos da Matemática Discreta pode significar diversificação da Matemática para além dos elementos algébricos, tão marcantes em estudantes da Escola Básica. É importante destacar que as Orientações Curriculares para o Ensino Médio sugerem discussão do uso de problema da Teoria dos Grafos:

No Ensino Médio, o termo "combinatória" está usualmente restrito ao estudo dos problemas de contagem, mas esse é apenas um de seus aspectos. Outros tipos de problemas poderiam ser trabalhados na escola são aqueles relativos a conjuntos finitos e com enunciados de simples entendimento relativo, mas não necessariamente fáceis de resolver. Um exemplo clássico é o problema das pontes de Königsberg, tratado por Euler (BRASIL, 2006, p. 94).

Na esfera estadual, o Currículo Básico da Escola Estadual do Espírito Santo prevê a “introdução à Teoria dos Grafos" (ESPÍRITO SANTO, 2009, p. 120) para o segundo ano do Ensino Médio e "resolução de problemas utilizando grafos" (ESPÍRITO SANTO, 2009, p. 122) para o terceiro ano. Em face da oportunidade de se buscar alternativas metodológicas para auxiliar o professor na abordagem da Teoria dos Grafos no Ensino Médio, nosso trabalho investigou contribuições da História da Matemática no ensino deste tópico (SÁ, 2014). Para este trabalho, em especial, procuramos estabelecer relações entre estratégias de resolução de alunos e a do matemático Leonard Euler, que criou a Teoria dos Grafos. 


\section{FUNDAMENTAÇÃO TEÓRICA}

Acreditamos que a História da Matemática é uma rica fonte de experiências e produções humanas, que oportuniza, dentre outras ações, um diálogo entre práticas atuais e fontes históricas, conforme previsto nas Orientações Curriculares para o Ensino Médio:

A utilização da História da Matemática em sala de aula também pode ser vista como um elemento importante no processo de atribuição de significados aos conceitos matemáticos. É importante, porém, que esse recurso não fique limitado à descrição de fatos ocorridos no passado ou à apresentação de biografias de matemáticos famosos. A recuperação do processo histórico de construção do conhecimento pode se tornar um importante elemento de contextualização dos objetos e de conhecimento que vão entrar na relação didática (BRASIL, 2006, p. 86).

Uma reflexão sobre a utilização da História na Educação Matemática nos conduz a uma escolha teórica. Os pontos de vista são variados e dependem da visão que cada professor e pesquisador têm da História e dos valores que estão presentes nesta metodologia. A primeira categorização referente ao uso de História da Matemática apresentada neste trabalho é proposta por Miguel e Miorim (2011). Estes autores organizam as investigações em: perspectiva evolucionista linear, perspectiva estrutural-construtivista operatória, perspectiva evolucionista descontínua, perspectiva sociocultural e perspectiva do Jogo de Vozes e Ecos. A perspectiva evolucionista linear recorre à História para identificar a ordem cronológica que os tópicos matemáticos surgiram e que, consequentemente, deverão ser ensinados. A perspectiva estrutural-construtivista operatória busca, na História, conflitos cognitivos que permitam a passagem de uma etapa de construção do pensamento para outra. Essa linha de pesquisa defende que os mecanismos de passagem de um período histórico são análogos aos da passagem de um estágio genético aos seus sucessores (PIAGET; GARCIA, 1987). Segundo a perspectiva evolucionista descontínua, a História permite reconhecer obstáculos epistemológicos e construir situações problemas para superá-los. Baseada nas ideias de Vygostky, a perspectiva sociocultural enxerga a História da Matemática 
como uma fonte de experiências humanas que podem ser trabalhadas em atividades didáticas de Matemática. Também comungando das ideias vygostkyanas, a perspectiva dos Jogos de Vozes e Ecos (BOERO; PEDEMONTE; ROBOTTI, 1997) busca na História da Matemática relações "entre as vozes históricas produzidas na sistematização do discurso teórico da Matemática e as vozes dos estudantes" (MOTTA, 2006, p. 17). Ao longo das atividades em sala de aula, nossa prática foi orientada pela Teoria do Jogo de Vozes e Ecos, pressuposto defendido não só em Miguel e Miorim (2011), mas também em Motta (2006) e Dynnikov e Sad (2007). Nossa proposta foi utilizar adaptações de um documento histórico que inicia discussões sobre a Teoria de Grafos como ponto de partida para a discussão desses conceitos, detalhamos mais um pouco sobre esse processo histórico na sequência.

\section{UMA BREVE INCURSÃO NA HISTÓRIA DA TEORIA DOS GRAFOS: CARTAS DE EULER E O PROBLEMA DAS PONTES DE KONIGSBERG}

No início do século XVIII, especula-se que os cidadãos da cidade russa de Konigsberg costumavam passar suas tardes de domingo a caminhar em torno de sua cidade. A própria cidade consistiu em quatro áreas de terra separadas pelo Rio Pregel sobre o qual há sete pontes, tal como ilustrado na Figura 1. O problema que os cidadãos fixaram era caminhar ao redor da cidade, cruzando cada uma das sete pontes apenas uma vez e, se possível, retornar ao seu ponto de partida.

Figura 1. Esboço da cidade de Könisberg

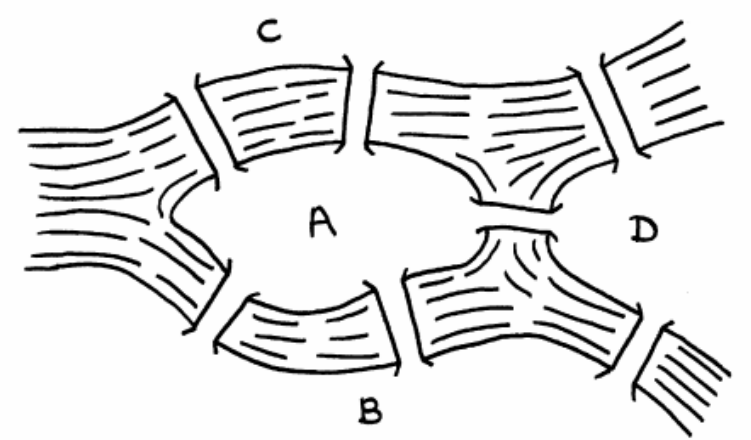

Fonte: Hopkins e Wilson (2004, p. 198) 
Em 1730, Leonhard Euler (1707-1783) chega à Rússia para ocupar a cadeira de Filosofia Natural na Academia de Ciências de São Petersburgo. Três anos mais tarde, com a saída Daniel Bernoulli (1700-1782), ele tornou-se o principal matemático da Academia, que, nessa época, tinha lançado uma revista de matemática, chamada de Commentarii Academia e Scientiarum Imperialis Petropolitanae. Esta revista foi, durante muito tempo, abastecida com contribuições de Euler. Segundo Boyer (1974, p. 324), "os editores não tinham que se preocupar com a falta de material enquanto a pena de Euler trabalhasse".

Após tomar conhecimento da notoriedade de Euler, em 1736, o prefeito de uma cidade próxima a Könisberg enviou uma carta ao matemático suíço em nome de Heinrich Kühn, um professor de matemática local. As mensagens trocadas inicialmente não foram recuperadas, mas uma carta datada de 09 de março indica que eles haviam discutido o problema. Parte dessa carta enviada a Euler está apresentada a seguir.

Você prestaria a mim e a nosso amigo Kühn o mais valioso serviço, colocando-nos muito em dívida com você, culto Senhor, se você nos enviasse a solução, que você conhece bem, para o problema das sete pontes Könisberg, juntamente com uma prova. [...] Eu adicionei um esboço das referidas pontes... (SACHS; STIEBITZ; WILSON, 1988, p. 134)1.

1 Tradução livre de "You would render to me and our friend Kuhn a most valuable service, putting us greatly in your debt, most learned sir, if you would send us the solution, which you know well, to the problem of the seven Konigsberg bridges together with a proof. [...] I have added a sketch of the said bridges". 
Figura 2. Esboço do mapa da cidade.

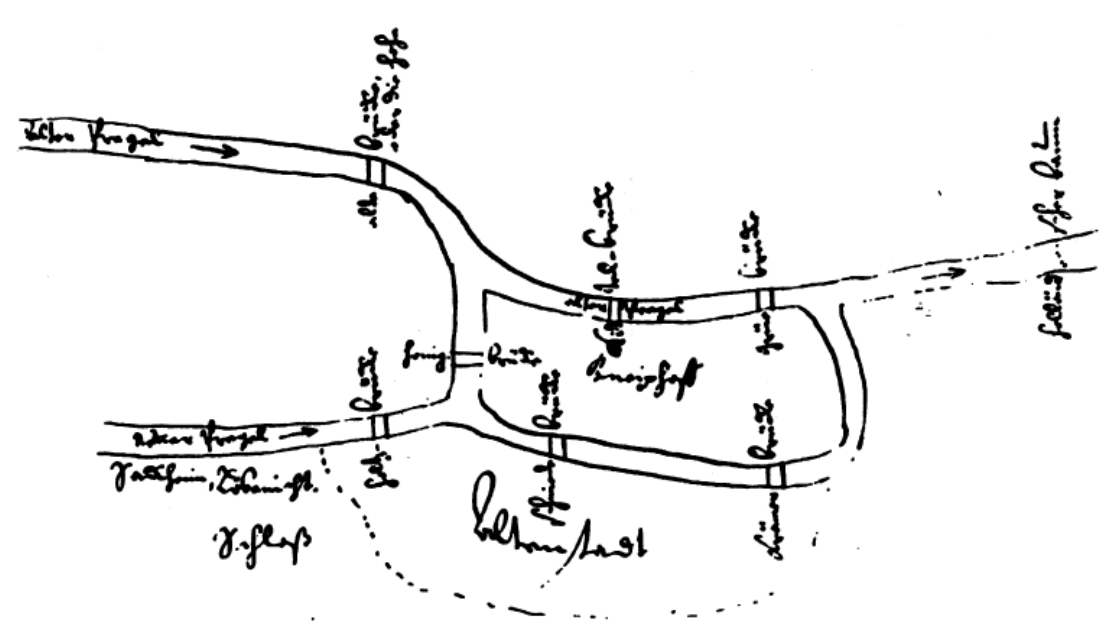

Fonte: Sachs, Stiebitz e Wilson (1988, p. 135).

Quatro dias após receber essa última mensagem do prefeito, Euler escreveu a Giovanni Jacopo Marinoni (1676-1755), um matemático e engenheiro italiano que morava em Viena. Na carta, parcialmente apresentada a seguir, o matemático suíço apresenta o problema das Sete Pontes de Königsberg e tece alguns comentários sobre o problema que ele recebera.

Um problema me foi apresentado sobre uma ilha na cidade de Königsberg, cercada por um rio, atravessado por sete pontes, e foi me perguntado se alguém poderia atravessar as pontes separadas em uma caminhada contínua de tal forma que cada ponte fosse atravessada apenas uma vez. Fui informado que até então ninguém havia demonstrado a possibilidade de fazer isso, ou mostrado que é impossível. Esta questão é tão banal, mas pareceu-me digno de atenção em que nem a geometria, álgebra, ou mesmo a arte de contar foram suficientes para resolvê-lo (HOPKINS; WILSON, 2004, p. 202) .

2 Tradução livre de "A problem was posed to me about an island in the city of Konigsberg, surrounded by a river spanned by seven bridges, and I was asked whether someone could traverse the separate bridges in a connected walk in such a way that each bridge is crossed only once. I was informed that hitherto no-one had demonstrated the possibility of doing this, or shown that it is impossible. This question is so banal, but seemed to me worthy of attention in that geometry, nor algebra, nor even the art of counting was sufficient to solve it". 
Figura 3. Parte da carta de Euler para Marinoni.

tid

Ti - The

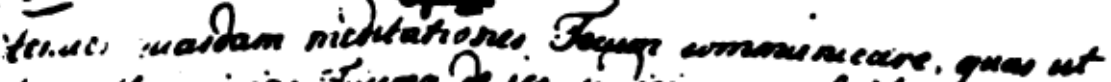

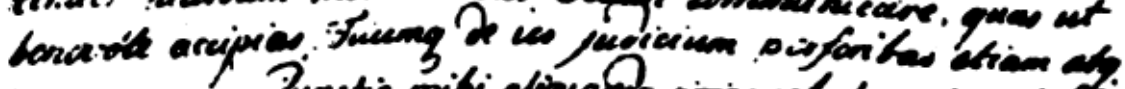

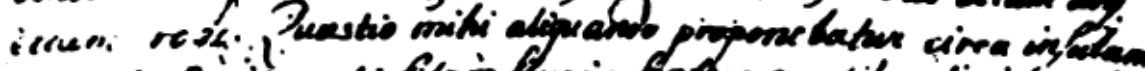

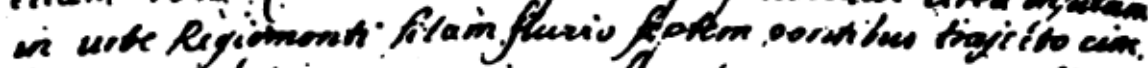

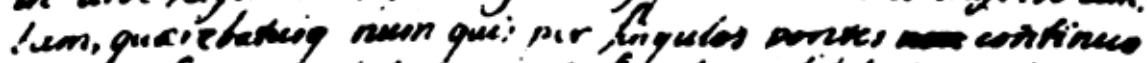

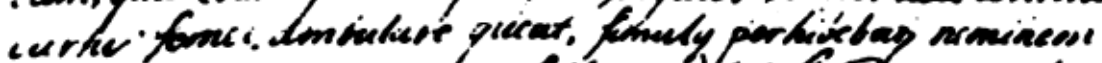

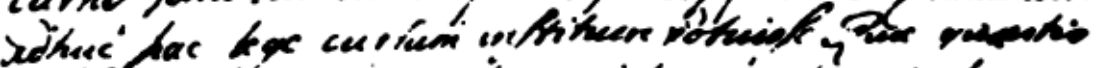

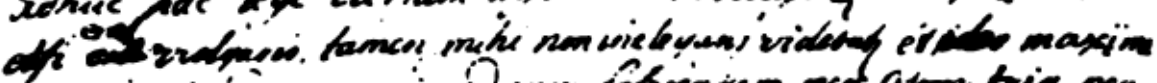

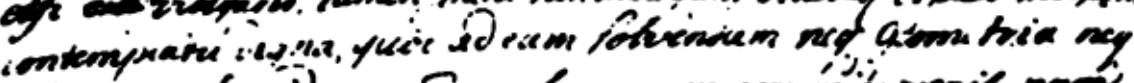

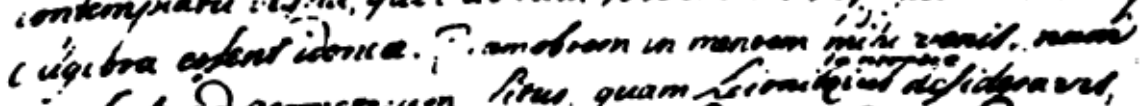

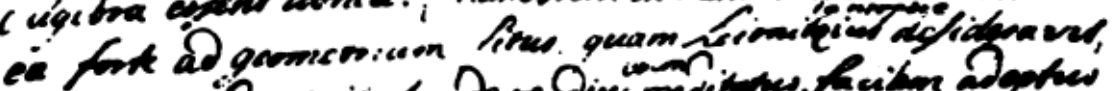

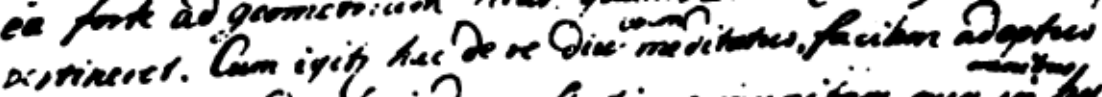

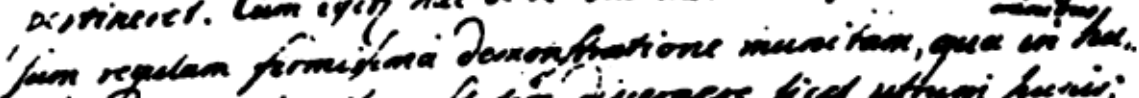

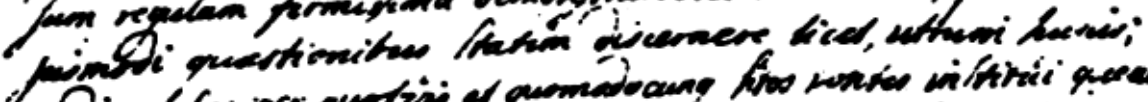

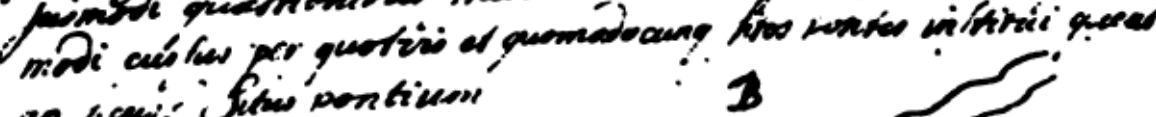

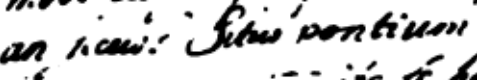

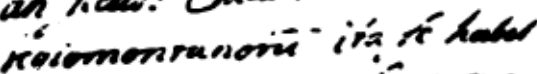

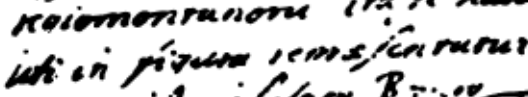

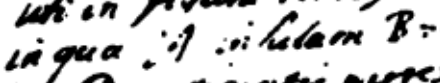
C. D. Dentincorioi aceres heriononis a kesisiu'm. -

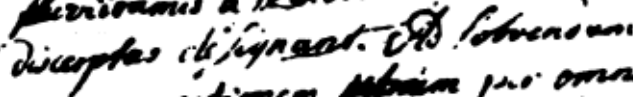

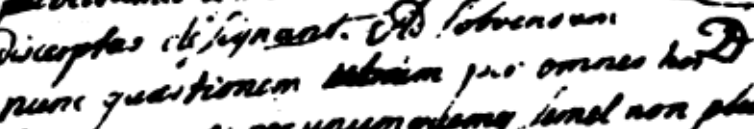

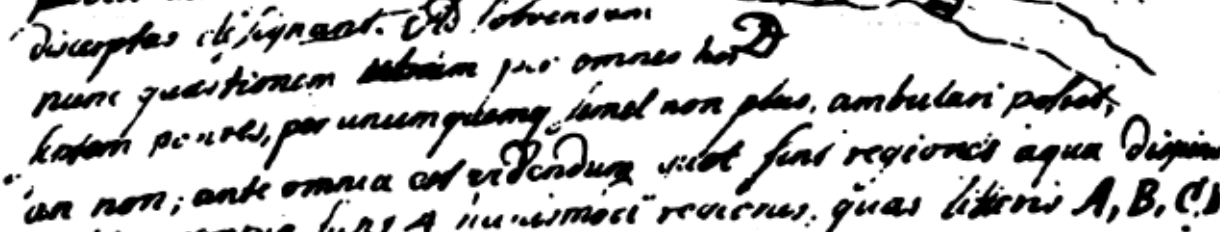

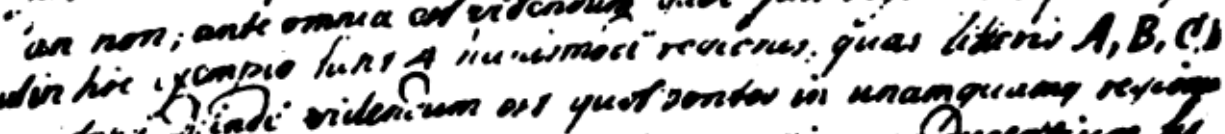

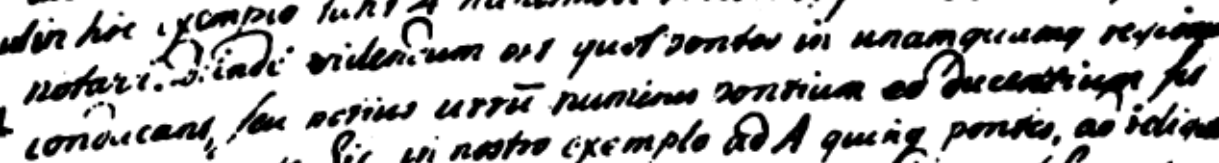

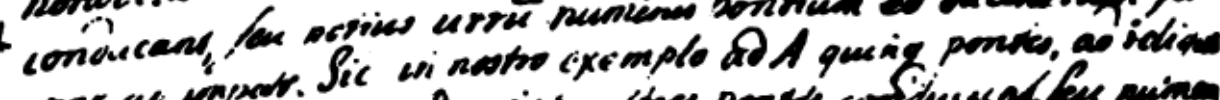

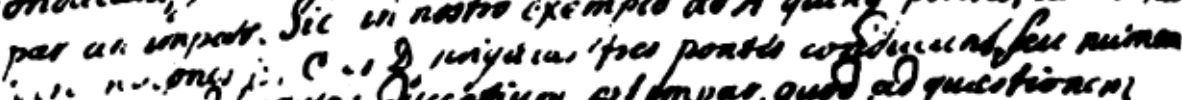

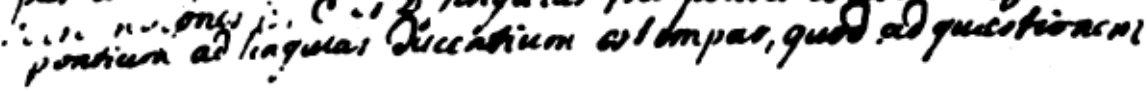

Fonte: Hopkins e Wilson (2004, p. 203)

Verificamos, então, que a partir do Problema das Pontes de Könisberg, Euler percebeu a necessidade de sistematizar um novo campo da Matemática - era o surgimento da Teoria dos Grafos. Euler não precisou de mais de uma quinzena para resolver o enigma. Para isso, ele criou um modelo matemático que simulasse a cidade russa, que é o que hoje chamados de grafo. Durante a elaboração do grafo, ele representou as porções de terra (ilhas e 
margens) por pontos e as pontes por linhas ligando esses pontos (figura 4).

Figura 4. Grafo que representa a cidade de Konisberg

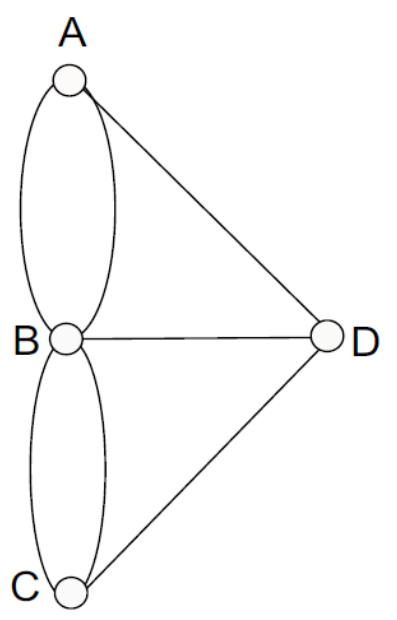

Fonte: Malta (2008, p. 12)

Apesar de não utilizar as denominações atuais da Teoria dos Grafos, Euler analisou a quantidade de arestas que incidem em cada vértice, ou seja, analisou o grau dos vértices. Então, o matemático percebeu que só se pode realizar um caminho passando em todas as pontes uma única vez se, e somente, cada porção de terra possuir uma quantidade par de pontes. Em homenagem ao matemático suíço, esse caminho é chamado de caminho euleriano. Mais formalmente, podemos enunciar essa observação do matemático suíço da seguinte forma:

Teorema:

(a) Se um grafo conexo tem mais de dois vértices com grau ímpar, então ele tem passeio euleriano.

(b) Se um grafo conexo tem exatamente dois vértices de grau ímpar, então ele possui um caminho euleriano aberto, que começa em um vértice, percorre todas as arestas e termina em um vértice diferente do inicial.

(c) Se um grafo conexo não tem vértices de grau ímpar, então ele tem um caminho euleriano fechado, que começa e termina no mesmo vértice, percorrendo todas as arestas. 
No dia 03 de abril de 1736, o matemático enviou a resposta ao prefeito da cidade próxima a Konisberg, apresentando sua solução para o problema e questionando o prefeito russo sobre a vinculação da Teoria dos Grafos à Matemática:

Assim você vê, mais nobre senhor, como este tipo de solução tem pouca relação com a matemática, e eu não entendo por que você espera que um matemático possa produzi-lo, ao invés de qualquer outra pessoa, já que a solução baseia-se na razão e sua descoberta não depende de qualquer princípio matemático. Devido a isso, eu não sei por que questões comuns que têm tão pouca relação com a matemática são resolvidas mais rapidamente pelos matemáticos do que por outros (HOPKINS; WILSON, 2004, p. 201).

Apesar de não vincular sua resolução do problema à matemática, Euler se interessou em divulgar sua análise para a comunidade científica da época. O matemático apresentou sua solução no artigo "Solutio problematis ad geometriam situs pertinentis", enviado ao Commentarii Academiae Scientiarum Imperialis Petropolitanae. O artigo, que foi escrito em latim e traduzido para o francês (EULER, 1851), é dividido em vinte e um parágrafos numerados, dos quais o primeiro atribui o problema à geometria da posição, os próximos oito são dedicados à solução do Problema das Sete Pontes de Könisberg e os demais generalizam o problema. Embora datado de 1736, o jornal de Euler só foi publicado em 1741, com reimpressão em 1752.

Após a resolução do Problema das Sete Pontes de Könisberg, começaram a surgir novos problemas, como o do Caixeiro Viajante, o das Quatro Cores e o do Carteiro Chinês, que permitiram o desenvolvimento da Teoria dos Grafos. Ainda assim, o problema de Euler e o de Hamilton, que foi discutido anos depois, formam os principais problemas históricos com Grafos. Por este motivo, escolhemos o primeiro para abordarmos. 


\section{PRESSUPOSTOS METODOLÓGICOS}

A sequência didática organizada para esta pesquisa foi composta por três atividades didáticas, que fizeram uso de história da Teoria dos Grafos na perspectiva da Teoria do Jogo de Vozes e Ecos. Retomando o percurso histórico, temos que, em 1736, o prefeito de uma cidade próxima a Königsberg enviou uma carta a Leonard Euler com o Problema das sete pontes. Assim, na atividade entregue para os alunos, realizamos pequenas adequações textuais a fim de aproximar a linguagem da carta ao contexto dos alunos. Apontamos a cidade de Vitória como foco de análise juntamente com suas pontes. A localização geográfica de Vitória contribuiu para esse processo por se tratar de uma ilha. Além da carta, elaboramos um material que apresenta o que se acredita ser a estratégia adotada por Euler (1851) para resolver o Problema das Sete Pontes de Königsberg. Também formulamos uma lista de problemas de sistematização do conteúdo.

Optamos, os pesquisadores e a professora regente em entregar a carta (figura 5) como tarefa de casa, realizar a atividade da história em duas aulas (uma para resolução e outra para discussão) e reservar uma aula para a atividade avaliativa. Destacamos que, neste texto, voltamos nossos olhares para o primeiro momento da sequência, entrega e resolução das cartas, pois objetivamos estabelecer relações entre estratégias de resolução de alunos e o do matemático Leonard Euler. 
Figura 5. Modelo de carta entregue aos alunos ${ }^{3}$.

Saudações!

Você prestaria um grande favor a mim e a professora Carla, se você nos enviasse a solução para o problema das seis pontes de Vitória, juntamente com uma justificativa. Nesta cidade há um rio atravessado por seis pontes e é perguntado se alguém pode atravessar todas as pontes de tal forma que cada ponte seja atravessada apenas uma vez. É possivel fazer isso e voltar ao ponto de partida? Adicionei um esboço das referidas pontes.

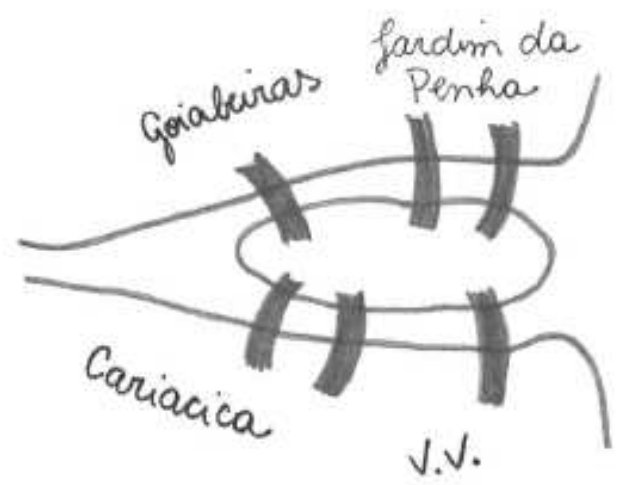

Aguardo resposta,

Lauro.

Fonte: Sá, 2014, p. 87.

\section{IMPLICAÇÕES EM SALA DE AULA}

As cartas foram entregues aos alunos pela professora regente. Na semana seguinte, iniciamos a aula recolhendo as cartas produzidas pelos alunos. Ao analisar os documentos, percebemos que os principais erros cometidos pelos alunos foram em decorrência da má

3 Nesta imagem fizemos uso de um nome fictício, mas na dinâmica realizada em sala de aula foi utilizado o verdadeiro nome da professora regente da turma. 
interpretação do enunciado do problema ou da figura apresentada. Durante a resolução empírica, alguns alunos cometeram três tipos de erro:

(i) Não procurou voltar ao ponto de partida (figura 6), o que indica que o aluno não se atentou para o questionamento sobre a possibilidade de se fazer o percurso e retornar ao ponto inicial. Nesse caso, o que ficou mais evidente para o aluno na carta é o fato de "atravessar todas de tal forma que cada ponte seja atravessada apenas uma vez".

Figura 6. Resolução empírica de um aluno da Turma B, com erro do tipo I.

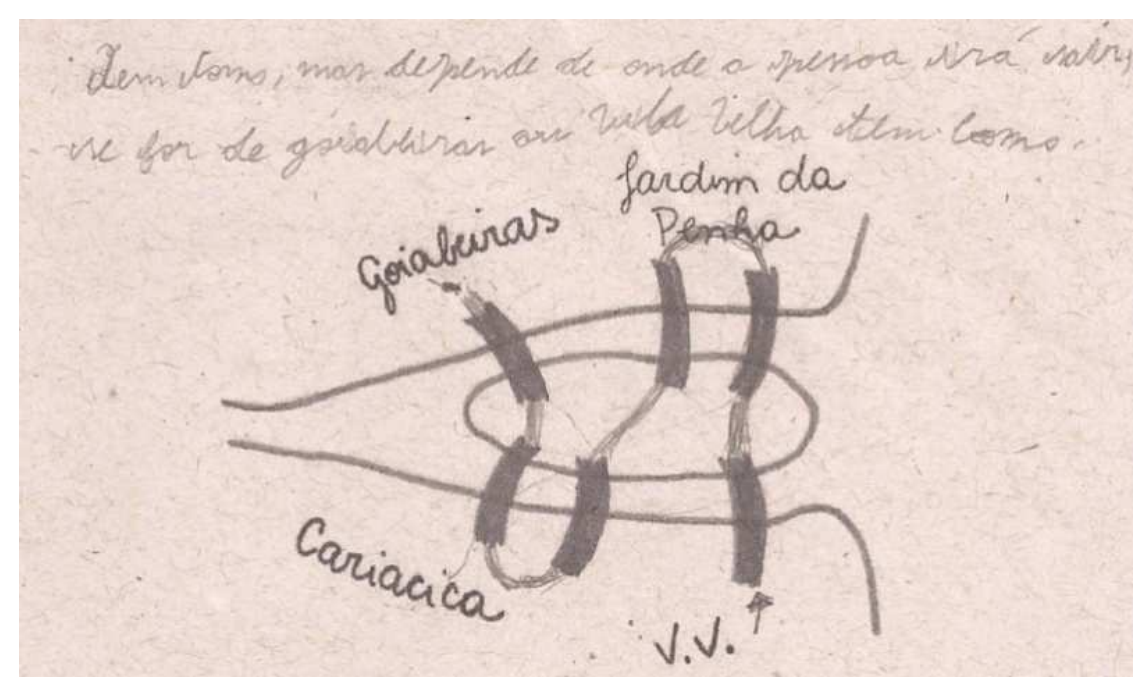

Fonte: Sá, 2014, p. 61.

Transcrição do texto: Tem como, mas depende de onde a pessoa irá sair; se for de Goiabeiras ou Vila Velha, tem como.

(ii) Passaram pela mesma ponte duas vezes (figura 7), o que indica que o aluno não se atentou para a orientação de cada ponte só deveria ser atravessada uma única vez. Em oposição ao erro relatado no caso anterior, verificamos que o aluno se atentou mais para o questionamento "É possível fazer isso e voltar ao ponto de partida?". 
Figura 7. Resolução empírica de um aluno da Turma A, com erro do tipo II.

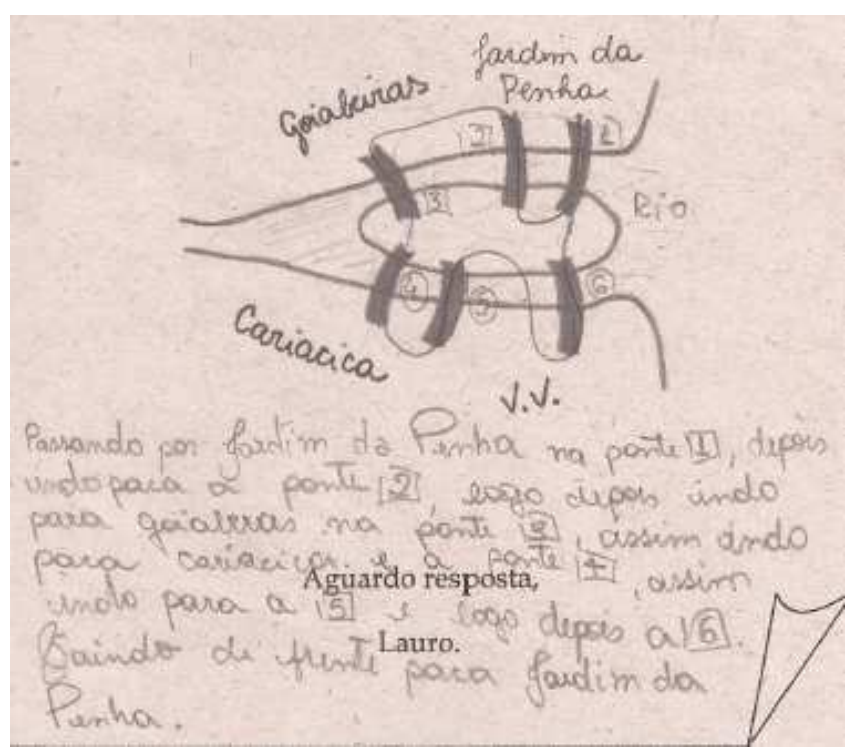

Fonte: Sá, 2014, p. 61.

Transcrição do texto: Passando por Jardim da Penha na ponte (1), depois indo para a ponte (2), logo depois indo para Goiabeiras na ponte (3), assim indo para Cariacica e a ponte (4), assim indo para a (5) e logo depois a (6). Saindo de frente para Jardim da Penha.

(iii) Não respeitaram a delimitação das pontes (Figura 8), o que aponta para uma não atribuição de significado ao modelo matemático, de modo que o aluno não percebeu que, na prática, estaria indo de Vila Velha à Vitória sem nenhum meio físico especificado.

Figura 8. Resolução empírica de um aluno da Turma A, com erro tipo III.

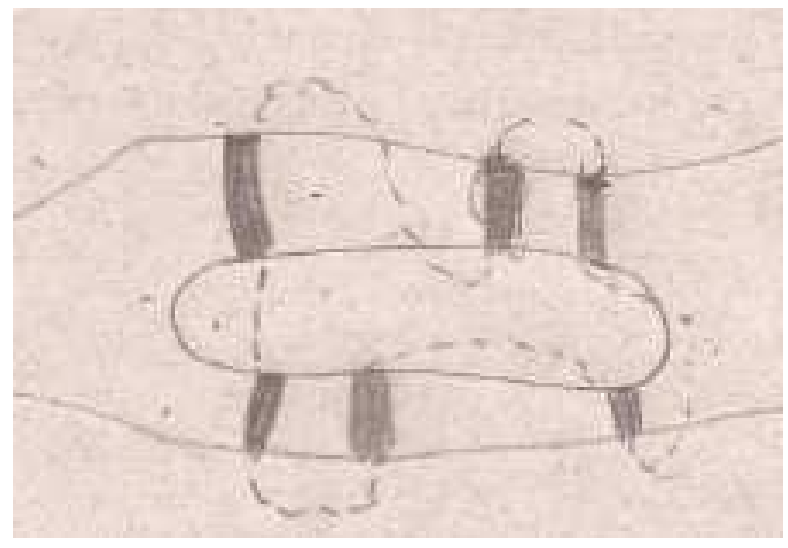

Fonte: Sá, 2014, p. 62. 
Um erro que não se enquadra nas tipologias apresentadas, mas que nos chamou atenção, está apresentado na figura 9. Na resolução da carta, o aluno tentou estabelecer uma relação entre a quantidade de pontes e de regiões. Na tentativa de usar o quociente entre a quantidade de regiões e a de pontes como argumento, ele demonstrou compreender que a impossibilidade de percurso no mapa apresentado decorre da quantidade de pontes, o que já é uma solução do problema de Teoria dos Grafos.

Figura 9. Resolução incorreta que apresenta rudimentos de Teoria dos Grafos.

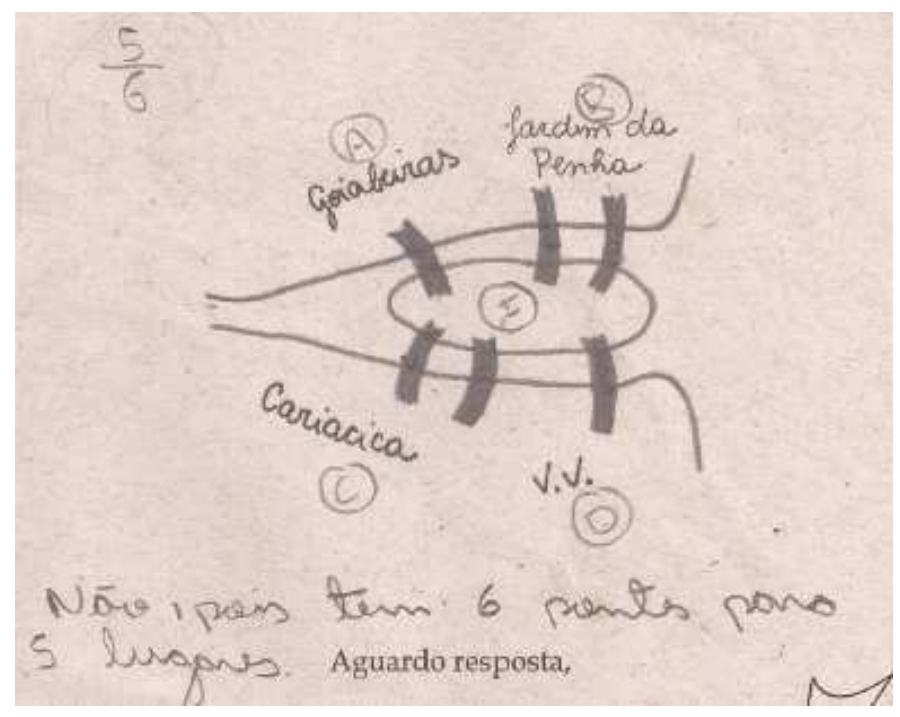

Fonte: Sá, 2014, p. 62.

Embora não tenham justificado sua resposta, alunos das duas turmas apresentaram uma alternativa de trajeto. Sabendo que não poderia ser realizado um percurso que passasse por todas as pontes e voltasse ao ponto de origem passando uma vez pelas pontes, os alunos comentaram que este percurso poderia ser realizado pela Rodovia do Contorno, como mostra a figura 10. 
Figura 10. Solução alternativa apresentada pelos alunos.

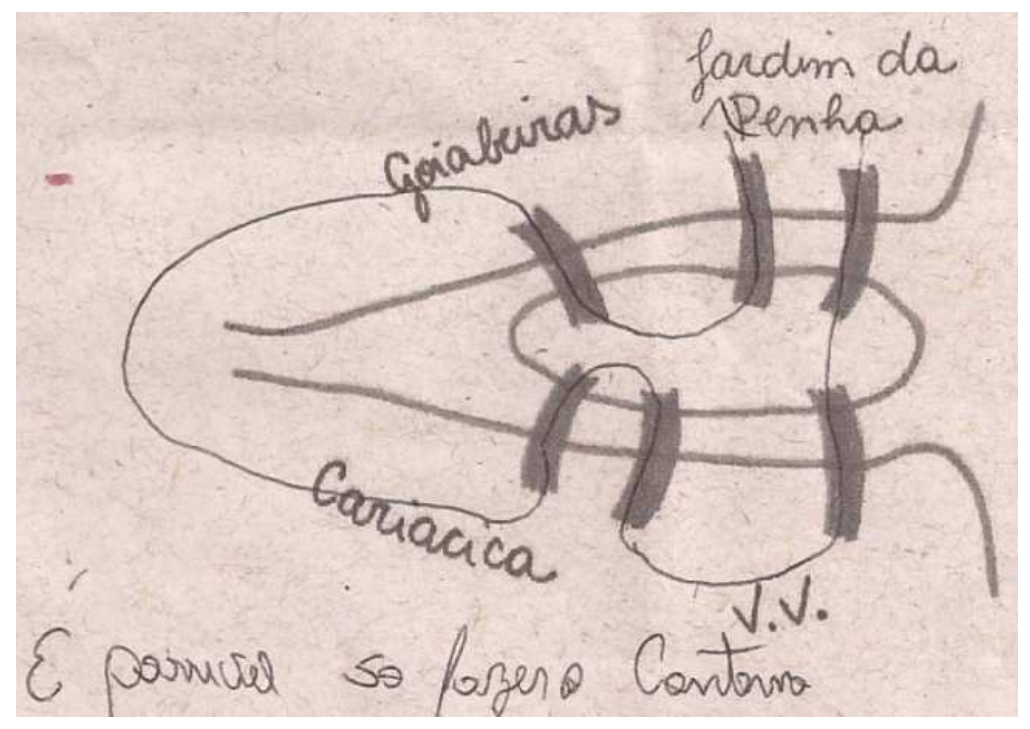

Fonte: Sá, 2014, p. 63.

Esta alternativa de trajeto já havia sido apresentada no estudo piloto, onde foi nos revelado que a Rodovia do Contorno atravessa o Rio Santa Maria da Vitória, como mostra a figura a seguir, e, portanto, pode ser considerada uma ponte.

Figura 11. Trecho da Rodovia do Contorno que atravessa o Rio Santa Maria da Vitória.

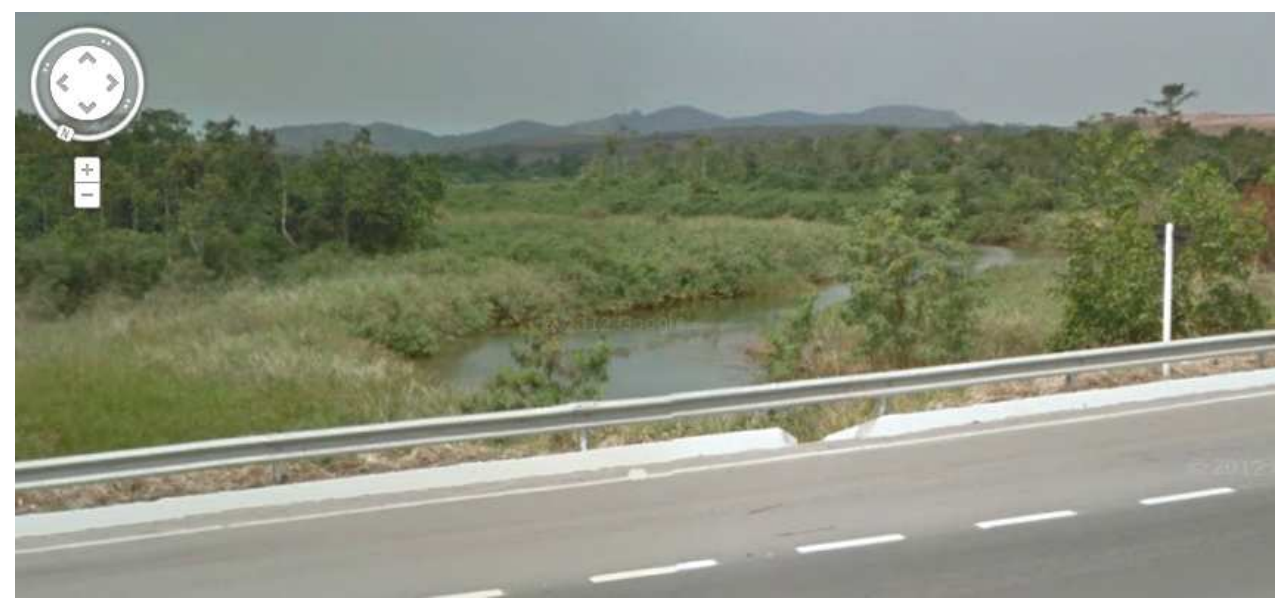

Fonte: Sá, 2014, p. 63.

Apenas um dos alunos conseguiu elaborar um enunciado que justifica a inexistência do caminho solicitado pela professora regente (figura 12). Ao dizer que "cada região (em cima e em baixo) deveriam ter um número par de pontes", o aluno apresenta o Teorema dos 
Caminhos Eulerianos no seu discurso. Assim, como utilizamos esta resolução para discutir a criação da Teoria dos Grafos, inferimos que a utilização da carta adaptada possibilita emergir discussões sobre aspectos básicos e iniciais sobre Grafos.

Figura 12. Resolução correta e com justificativa.

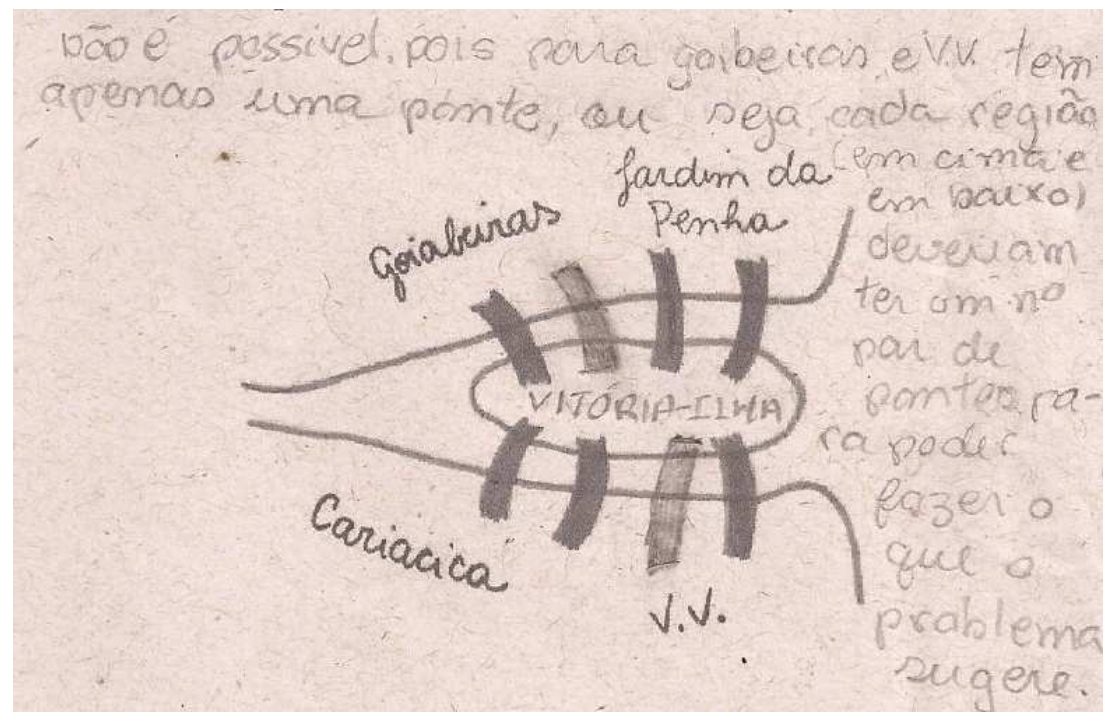

Fonte: Sá, 2014, p. 64.

Transcrição do texto: Não é possível, pois para Goiabeiras e V.V.

tem apenas uma ponte, ou seja, cada região (em cima e em baixo)

deveriam ter um no par de pontes para poder fazer o que o problema sugere.

Analisando a resolução do aluno, percebemos que ao dizer que "cada região (em cima e em baixo) deveriam ter um número par de pontes", ele apresenta uma ideia do Teorema dos Caminhos Eulerianos no seu discurso.

Dando continuidade à aula, entregamos a atividade que narra o processo de construção da Teoria dos Grafos, por Euler. Para leitura do texto e resolução das questões, os alunos se organizaram em duplas ou em trios, que foram designados pelos próprios alunos. Antes de iniciar a correção das atividades, retomamos algumas respostas das cartas produzidas pelos alunos para questioná-los sobre o nível de dificuldade do problema resolvido por Euler. Nesse momento, alunos de ambas as turmas comentaram que o problema não era difícil e 
que eles perceberam que a inexistência do caminho solicitado na carta decorria da quantidade ímpar de pontes de cada região do mapa. Ainda assim, eles julgaram que tal observação não era pertinente, pois não perceberam que esta seria uma justificativa aceitável para o problema. Nesse momento, destacamos que a História da Matemática também contribui para mostrar que o raciocínio dedutivo também tem importância na matemática. Após relacionar as respostas dos alunos com a resolução de Euler, demos continuidade à discussão das atividades e correção das questões.

\section{CONSIDERAÇÕES FINAIS}

A partir do exposto, foi possível estabelecer relações entre estratégias de resolução de alunos e do matemático Euler. Verificamos que alguns alunos apresentaram rudimentos do Teorema da Existência do Caminho Euleriano e, além disso, um aluno enunciou o teorema durante a resolução do Problema das Pontes de Vitória. Com efeito, essas cartas foram utilizadas como disparador da discussão da solução de Euler. Na ocasião, formalizamos que se um grafo conexo tem mais de dois vértices com grau ímpar, então ele não possui passeio euleriano. Com efeito, destacamos que (i) se um grafo conexo tem exatamente dois vértices de grau ímpar, então ele possui um caminho euleriano aberto, que começa em um vértice, percorre todas as arestas e termina em um vértice diferente do inicial e que (ii) se um grafo conexo não tem vértices de grau ímpar, então ele tem um caminho euleriano fechado, que começa e termina no mesmo vértice, percorrendo todas as arestas.

Com essa experiência, entendemos que algumas contribuições da História da Matemática na abordagem da Teoria dos Grafos no Ensino Médio são de caráter cognitivo e social. Por caráter cognitivo, entendemos que os ecos produzidos pelos alunos durante a atividade proposta apontam para uma apropriação do conhecimento facilitado por meio do uso da História da Matemática. Por caráter social, destacamos que a perspectiva histórica nos permite mostrar que a matemática é uma ciência em contínuo desenvolvimento e que este processo é fruto de trabalho de diversas as pessoas. 


\section{AGRADECIMENTOS}

Agradecemos aos membros do Grupo de Estudo em Educação Matemática do Espírito Santo (Geem/ES) e do Grupo de Estudos e Pesquisas em Práticas Pedagógicas de Matemática (Grupem/Ifes) pelas contribuições a este estudo e aos professores, pedagogas, coordenadora e, especialmente, alunos da escola-campo, por acreditarem nesta pesquisa e por viabilizarem seu desenvolvimento. Também agradecemos aos professores Michael Hardy (Saint Xavier University), Dominic Klyve (Central Washington University) e Lee Stemkoski (Adelphi University), pelos materiais fornecidos e pelas indicações dadas.

\section{REFERÊNCIAS}

BOERO, P.; PEDEMONTE, B.; ROBOTTI, E. Approaching theoretical knowledge through voices and echoes: a vygotskian perspective. Em: PME CONFERENCE, 21nd, Finlândia. Proceedings... $1997 . \quad$ Disponível em: <http://www.dm.unito.it/semdidattica/2011/app/boero21.pdf>. Acesso em: 21 out. 2013. BOYER, C. B. História da Matemática. São Paulo: Edgard Bücher, 1974.

BRASIL. Secretaria de Educação Básica. PCN+ Ensino Médio: Orientações Educacionais Complementares aos Parâmetros Curriculares Nacionais - Ciências da Natureza, Matemática e suas Tecnologias. Brasília, Brasil: MEC/SEF, 2002.

BRASIL. Orientações curriculares para o Ensino Médio: Ciências da natureza, matemática e suas tecnologias. Brasília, Brasil: MEC/SEF, 2006.

DYNNIKOV, C. M. S. DA S.; SAD, L. A. Uma abordagem pedagógica para o uso de fontes originais em História da Matemática. Guarapuava, Paraná, Brasil: SBHMat, 2007.

ESPÍRITO SANTO. Secretaria da Educação. Currículo Básico Escola Estadual - Ensino Médio: área de Ciências da Natureza. Vitória: SEDU, 2009. Disponível em: <http://www.educacao.es.gov.br/download/SEDU_Curriculo_Basico_Escola_Estadual.pdf>. Acesso em: 06 out. 2012.

EULER, L. Solution d'um problème appartenant à la géométrie de situation, par Euler. Nouvelles Annales de Mathématiques, 10, 106-119. 1851. Traduzido do Latim por E. Coupy. 
HOPKINS, B.; WILSON, R. J. The truth about Konisberg. The College Mathematics Journal, vol. 35, n. 03, p. 198-207, maio, 2004.

MALTA, G. H. S. Grafos no Ensino Médio: uma inserção possível. 2008. 158f. Dissertação (Mestrado em Ensino de Matemática) - Programa de Pós-Graduação em Ensino de Matemática, Universidade Federal do Rio Grande do Sul, Porto Alegre, 2008.

MIGUEL, A.; MIORIM, M. A. História na Educação Matemática: propostas e desafios. Belo Horizonte, Brasil: Autêntica Editora, 2011.

MOTTA, C. D. V. B.. História da Matemática na Educação Matemática: espelho ou pintura?. Santos, São Paulo, Brasil: Comunicar, 2006.

PIAGET, J.; GARCIA, R. Psicogénese e história das ciências. Lisboa, Portugal: Dom Quixote, 1987.

SÁ, L. C. História da Teoria dos Grafos e algumas contribuições no Ensino Médio. Trabalho de Conclusão de Curso (Licenciatura em Matemática) - Instituto Federal do Espírito Santo, Vitória - Espírito Santo, Brasil, 2014.

SACHS, H.; STIEBITZ, M.; WILSON, R. J. An historical note: Euler's Konisberg Letters. Journal of Graph Theory, vol. 12, n. 01, p. 133-139, 1988. 